This is preprint of a paper that has been accepted for publication in Annals of the New York Academy of Sciences. Please cite the published version when it is available.

\title{
The Nature of Beauty: behavior, cognition, and neurobiology
}

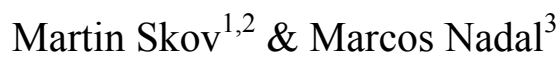 \\ ${ }^{1}$ Danish Research Centre for Magnetic Resonance, Copenhagen University Hospital, \\ Kettegaards Alle 30, DK-2650 Hvidovre, Denmark \\ ${ }^{2}$ Decision Neuroscience Research Cluster, Copenhagen Business School, Solbjerg \\ Plads 3, DK-2000 Frederiksberg, Denmark \\ ${ }^{3}$ Human Evolution and Cognition Group, University of the Balearic Islands, \\ Department of Psychology, Palma, Spain \\ E-mail: martins@drcmr.dk (M.S.),marcos.nadal@uib.es (M.N)
}

\begin{abstract}
Beauty is commonly used to refer to positive evaluative appraisals that are uniquely human. Little is known, however, about what distinguishes beauty in terms of psychological function or neurobiological mechanisms. This review describes recent empirical studies, and synthesizes what behavioral, cognitive, and neuroscientific experiments have revealed about the nature of beauty. These findings suggest that beauty shares computational mechanisms with other forms of hedonic appraisal of sensory objects, but is distinguished by specific conceptual expectations. Specifically, experiencing an object as pleasurable is a prerequisite for judging it as beautiful, but to qualify as "beautiful" an object must elicit especially high levels of pleasure and be matched to internal learned models of what counts as beauty. We discuss how these empirical findings contradict several assumptions about beauty, including the notion that beauty is disinterested, and that it is specific to Homo sapiens.
\end{abstract}

Keywords: beauty, pleasure, neuroaesthetics, mate choice, decision-making 
Beauty is currently attracting more attention from biologists, neuroscientists, and psychologists than ever before. According to Web of Science, about 20,000 papers have been published on beauty since 1970. Of these, 13,000 have been written just in the last decade. There are several reasons for this recent surge. With a beauty industry in perpetual expansion, and a growing concern about self-representation on social media (e.g. many apps now include "beauty filters" for selfies and online meetings), the role beauty plays in human society has become of great interest to social, behavioral, and brain scientists. ${ }^{1}$ At the same time, advances in neuroimaging methods have allowed neuroscientists to search for the biological basis of beauty appreciation. ${ }^{2-6}$ Finally, growing evidence for complex perceptual, cognitive, and affective mechanisms involved in animal mate choice has raised questions about the role beauty plays in driving sexual selection. ${ }^{7-9}$ These and other factors have allowed and encouraged scientific research into the psychological and biological factors determining why some objects are experienced as beautiful, while others are not, and how beauty affects choices, psychological wellbeing, and social interactions.

Yet, despite this remarkable output of publications, beauty is rarely defined in clear behavioral, psychological, or neurobiological terms. It is even unclear whether scientists working on different aspects of beauty share a common understanding of what beauty is. If beauty denotes a specific evaluative response that humans can have to sensory objects - this flower is beautiful - a scientific account of beauty requires characterizing what is distinct about it. So far, however, neither psychology nor neurobiology have succeeded in showing how beauty appraisals differ from other forms of sensory appraisal. ${ }^{10,11}$ There are several overviews of neuroscientific research on aesthetic appreciation ${ }^{2,5,12-14}$ and facial attractiveness. ${ }^{15-18}$ But no review paper has tried to summarize what is known about beauty as a psychological and neurobiological phenomenon per se.

Our goal here is to amend this situation by synthesizing what the scientific evidence has to say about the nature of beauty. Our main aim is to elucidate what is known about beauty as a behavioral, psychological, and neurobiological phenomenon. We discuss whether empirical findings support the distinction of beauty from other types of sensory evaluation, whether beauty owes to specifically human psychological or neurobiological features, and the ways in which experiencing something as beautiful influences the way we interact with it. 


\section{From Philosophy to Science}

Beauty is first and foremost a philosophical idea. ${ }^{19,20}$ For most of its history, the idea of beauty has been discussed without any detailed understanding of human biology or psychology. In the Western tradition, systematic thinking about beauty goes back several thousand years, at least to the Classical Greeks. To these early philosophers, the idea of beauty was a broad concept. They used the word "beautiful" (kalos) to mean almost the same as the word "good" (agathos). Beautiful meant good and pleasant, and could be applied to architecture, sculpture, the human body, but also to people's characters, a city's laws, and governance. Beauty took the form of harmony when referring to sound, and of symmetry when referring to vision. Beauty was found in order - the arrangement and proportion among parts — and in the appropriateness of things to their end - their adequacy, aptness, and suitability. In all of these cases, beauty was conceived as a property of objects, not as a subjective response to them. ${ }^{21-23}$

This Great Theory of Beauty ${ }^{24}$ prevailed for close to two thousand years. But several factors contributed to its demise during the $18^{\text {th }}$ century. Classic art, which had been the tangible justification for the Great Theory of Beauty, gave way to Baroque and Romantic art. But most importantly, in response to Cartesian rationalism and to universal principles of reason, Empiricism elevated human experience as the seat of knowledge and feeling. In line with this, the British Empiricists rejected the notion of beauty as residing in objects in favor of a notion of beauty as a quality of human understanding. Beauty was now conceived as an internal sense, as a kind of pleasurable judgment of complex features that exhibit some form of arrangement. ${ }^{25,26}$ The key to understanding beauty was no longer found in the properties of objects; it was now found in certain qualities of aesthetic judgment that made it reliable and legitimate. The most influential of these qualities was disinterestedness: judgments of taste should be impartial, not based on the prospect of personal benefit or advantage. The German philosopher Immanuel Kant also saw disinterestedness as the key to legitimate and universal judgments based on the pleasure of perceptually apprehending something. ${ }^{27}$ Kant placed aesthetics, as the philosophical theory of art and beauty, on equal standing with the theory of truth (metaphysics and epistemology) and the theory of good (ethics). 
Originally, disinterestedness did not refer to a quality dimension of experience. ${ }^{28}$ Rather, it was a quality of aesthetic judgments. But with the "art for art's sake" movement of the $19^{\text {th }}$ century, disinterestedness came to be regarded the crucial quality of the experience of beauty. ${ }^{29-31}$ Since art was viewed as valuable for its own sake rather than as a subordinate means to other values, such as worship, glorification, celebration, or entertainment, it was considered to have no other use than to be aesthetically experienced, and this required absolute disinterestedness. Only completely useless things, those that reveal no use or need, could be appreciated aesthetically.

The avant-garde movements and art theory of the $20^{\text {th }}$ century contested and rejected the entangled notions of a distinct aesthetic disposition, the separation of aesthetic experiences from other common experiences of life, and the privileged status of beauty. But by then these ideas had already filtered into psychology and neuroscience and crystalized as tacit assumptions. It was taken for granted that beauty is a specific kind of (disinterested) pleasure, elicited only by certain objects (faces, art, nature). For instance, Valentine wrote in his 1962 book The Experimental Psychology of Beauty: "We should hardly call the pleasurable sensations due to a satisfying meal 'beautiful'” (p. 9). Even today, these unquestioned assumptions continue to influence the way scientists conceive beauty. Beauty is seen as the purview of such fields as empirical aesthetics, social psychology and reconstructive surgery, possibly sexual selection and mate choice, but certainly not fields concerned with motivation, or the pleasure of food, drink or touch. ${ }^{33}$

\section{Beauty as a Scientific Problem}

The psychologist Daniel Berlyne, who, in the 1970s, put empirical aesthetics on a biological footing, understood beauty as pleasure from perception. ${ }^{34,35}$ In the same line, in psychology and neuroscience, beauty is currently conceived as a form of sensory appraisal, an affective response that people may have when they encounter sensory objects. ${ }^{3,12,14,15}$ Most experiments investigating this response seek to understand why it arises: what are the factors that make an object appear beautiful? Since there is no independent biological marker that can be used to identify neurobiological states as beautiful, all such studies rely on subjects reporting whether 
they experience something as beautiful or not. Based on such evaluations, scientists can ask if beauty responses are elicited by specific perceptual properties, and try to chart the neural processes necessary for their generation. ${ }^{2,5,13,14,36}$

Over the last 150 years, influenced by the philosophical tradition mentioned above, hundreds of behavioral studies have sought to determine which sensory features people find beautiful by systematically manipulating stimulus properties. While these studies have found some stimulus properties to be reliably associated with beauty responses in most people - e.g., symmetry or facial averageness in the visual domain; ${ }^{37-39}$ consonance or expectancy violations in the auditory domain ${ }^{40-43}$ they have also revealed that beauty responses are not fixed. ${ }^{44-46}$ Not only do people differ in how beautiful they find a stimulus property but, depending on context and circumstances, even the same person can find the same stimulus beautiful on one occasion but not on another.

Based on such findings, neuroscientists have recently revised their model of how aesthetic evaluations take place. ${ }^{47,48}$ Aesthetic evaluations of sensory objects are no longer thought of as reflexive hardwired - perhaps even innate - responses to object features. Determining whether a stimulus is liked or disliked also involves integrating factors signaling the internal state of the organism, expectations for the sensory object being evaluated, and cognitive demands related to plans and on-going behavior (Figure 1). Rather than finding specific perceptual features beautiful regardless of context, people evaluate the hedonic value of the sensory objects in a flexible way, allowing them to estimate how rewarding the object will be in the context of their current needs and behavioral concerns. ${ }^{49}$ 


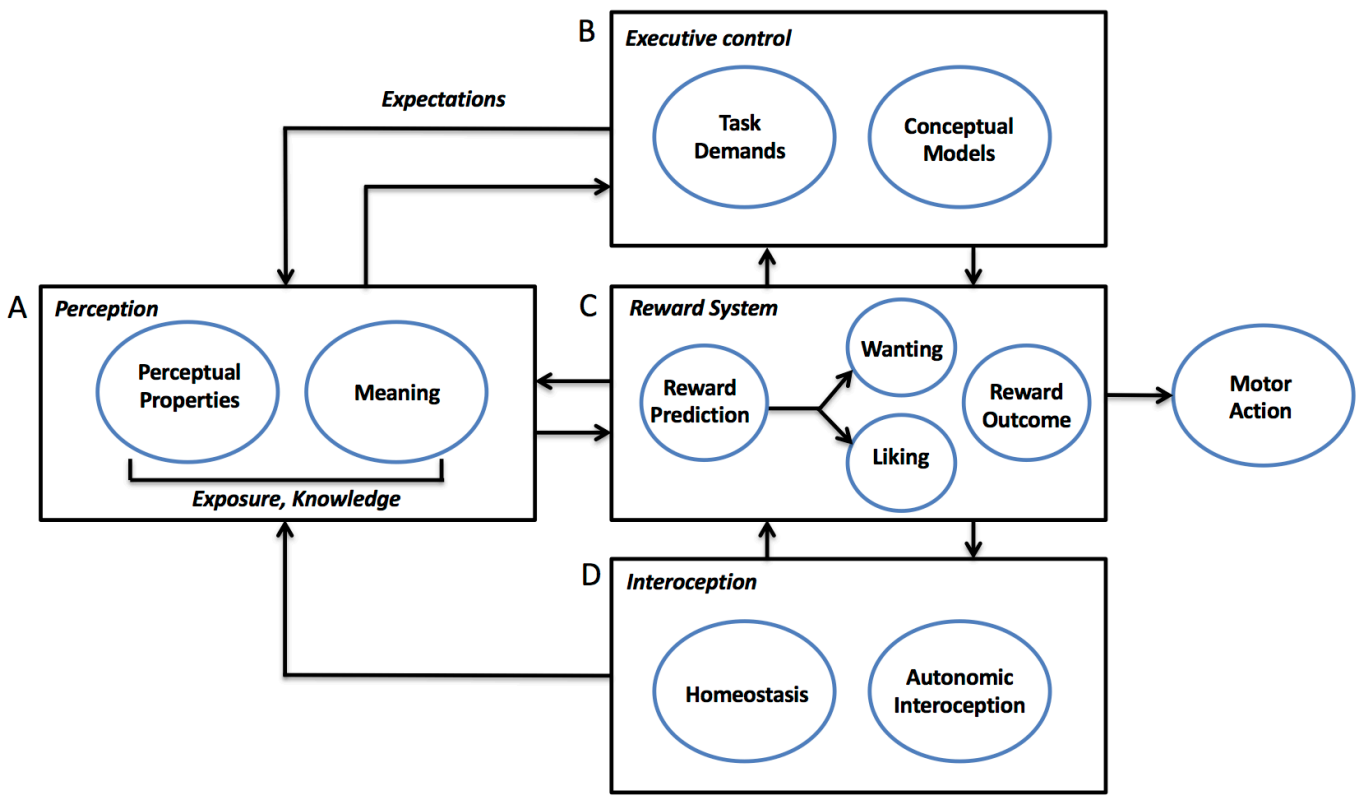

Figure 1. Factors known to affect the computation of aesthetic appraisal. Aesthetic evaluations involve the attribution of hedonic value to sensory input. As a rule of thumb, we like sensory objects that evoke pleasure and dislike objects that evoke displeasure. Empirical evidence suggests that hedonic values are computed by different reward mechanisms in the reward system $(\mathrm{C})$. While it remains unclear why some perceptual representations (A) trigger pleasure, and other displeasure, studies have found evidence that aesthetic liking varies with several different perceptual mechanisms. Complicating the picture further is the fact that reward processes are modulated both by interoceptive information (D), signaling the internal state of the body, and expectations about the stimulus that arise from executive mechanisms involved in the control of behavior (B). Such task-related expectations also influence how a stimulus is being perceptually represented. Aesthetic evaluations are therefore best conceived of as temporal events where the brain assesses how valuable a given sensory object is in the context of current needs and behavioral goals.

Current evidence from human neuroimaging experiments suggests that aesthetic evaluations rely on the engagement of neural nuclei that generate degrees of pleasure and displeasure. ${ }^{50-55}$ These neurons are distributed across the mesocorticolimbic reward circuit, including the nucleus accumbens, caudate nucleus, pallidum, amygdala, orbitofrontal cortex (OFC), anterior cingulate cortex (ACC), and the insula (Figure 2). Liking is assumed to be associated with the generation of states of pleasure, ${ }^{49}$ while disliking is thought to involve the generation of negative emotions, ${ }^{56}$ perhaps especially disgust. ${ }^{57}$ While these affective states correlate with 
specific regions of the reward circuit in animal models, ${ }^{58}$ current understanding suggests that liking and disliking in humans rely on distributed networks of activity that involve multiple anatomical regions. ${ }^{49,59}$

Furthermore, hedonic evaluations do not only engage liking and disliking processes. They also initiate wanting processes that reflect the expected reward value of the object being assessed (Figure 1). ${ }^{60}$ Wanting processes modulate perceptual and executive processes, prompting the object to become both more salient and desirable, thereby influencing behavior. ${ }^{61}$ Reinforcement learning models ${ }^{62,63}$ suggest that organisms use their experiences of how likable an object is to form habits about which parts of the world it should approach, and which it should avoid.
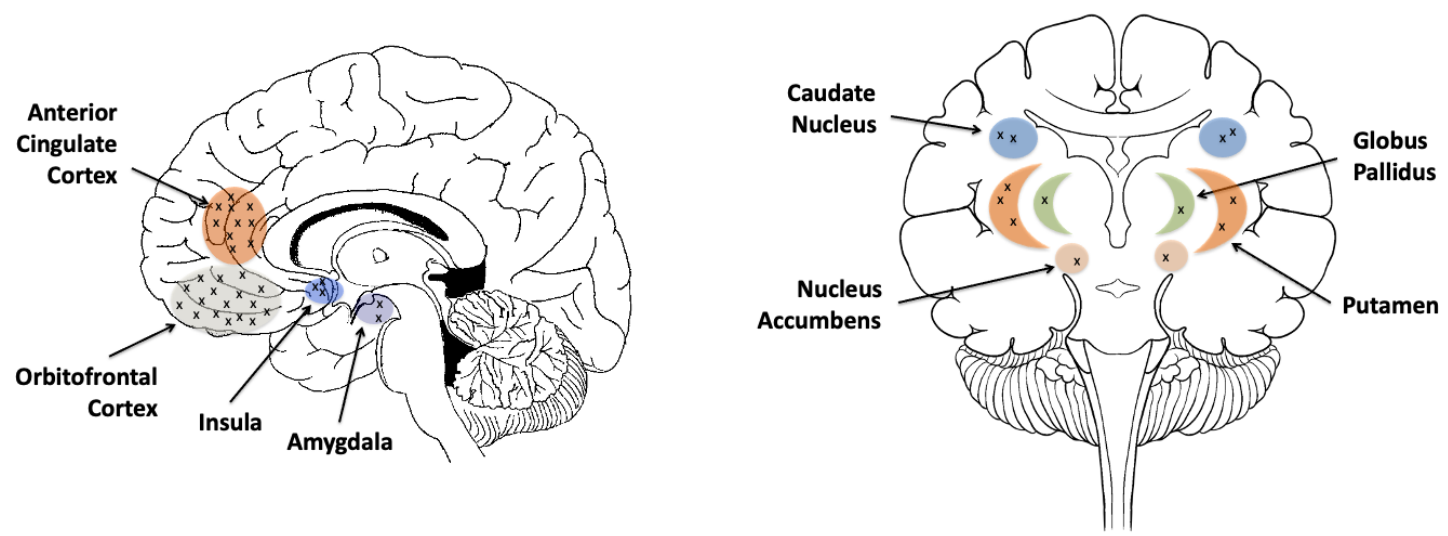

Figure 2. Neural correlates of beauty. Representation of data from 18 fMRI studies reporting neural correlates specifically for beauty judgments. ${ }^{64-81}$ The figure depicts the distribution of reported activity as it is located across the reward circuitry. Each $x$ indicates that a study reported activity for beauty judgments in the depicted anatomical region.

Neuroimaging experiments that have used beauty judgments as a specific evaluation task have found that beauty evaluations also correlate with activity in multiple reward structures (Figure 2). ${ }^{64-81}$ Since most of these experiments report enhanced activity in the medial OFC and the anterior part of ACC, some researchers ${ }^{68}$ have argued that beauty responses may be associated with a specifically dedicated region in the medial OFC. However, statistical meta-analyses that include a range of different evaluation experiments, including several of the beauty experiments reviewed here, suggest that medial OFC is a common computational hub for many types of positive hedonic evaluations. ${ }^{50,51,52,53,54}$ At least based on the small set of 
imaging studies that have so far employed beauty judgment as an evaluation task, it appears that neural activity underlying beauty evaluations overlaps with that of other types of hedonic evaluations.

Having said that, the evidence currently available does not allow us to model the computational architecture for beauty evaluations in detail. Findings from nonbeauty experiments suggest that contextual conditions, such as attending explicitly to an object with the purpose of evaluating it versus evaluating it implicitly, modulate how parts of the reward circuit become engaged. ${ }^{68,73,82-84}$ It remains to be seen if beauty evaluations are associated with specific flows of information from sensory systems to individual reward mechanisms, including signals associated with reward prediction and outcome, liking and wanting, and so on. Ascertaining whether beauty evaluations engage, say, wanting signals in a unique way requires imaging experiments that directly compare beauty evaluation tasks to other types of aesthetic evaluation, such as liking or attractiveness.

\section{Beauty and Pleasure}

The neuroimaging literature described above suggests that we experience an object as beautiful when beauty evaluations tap into pleasure mechanisms employed by diverse hedonic evaluations. ${ }^{9,48,49,85}$ Pleasure is believed to have evolved as a mechanism that helps motivate organisms to seek out environmental features and resources that are necessary to their survival, and therefore evolved early along the vertebrate lineage. ${ }^{86,87}$ Neurobiological processes associated with the generation of pleasure are highly conserved across species, raising the possibility that human beauty responses are not really unique, that they employ neural mechanisms also engaged by other pleasure experiences. As noted, both philosophers and psychologists have long assumed that beauty can be distinguished from more "basic" forms of pleasure, but empirical support for this proposition is scant.

Experiments where the same pool of stimuli are rated according to different kinds of evaluative judgments, such as pleasantness, liking, or beauty, have consistently found that beauty judgments are highly correlated with pleasure ratings. ${ }^{88-93}$ In one of our own studies where subjects rated photographs of interior architectural spaces both according to beauty and pleasure, pleasure ratings predicted beauty ratings, and accounted for $58 \%$ of their variance. ${ }^{77}$ Furthermore, studies using 
factor analysis have found that beauty and other evaluative judgments load onto a common factor, ${ }^{94-98}$ referred to by Berlyne as hedonic tone ${ }^{89}$ or hedonic value. ${ }^{88,95}$

Comparing behavioral data does not show that beauty responses are neurobiologically identical to hedonic pleasure responses. To make this claim, neuroscientists need to manipulate the state of pleasure experienced for a sensory object. One way this can be accomplished is by inhibiting opioid signaling in neurons responsible for generating pleasure. Several intervention studies in animals and humans ${ }^{58,99}$ have demonstrated that blocking $\mu$-opioid receptors in ventral striatum or OFC significantly reduces pleasure responses. In humans, Chelnokova and colleagues ${ }^{100}$ found that ingesting naltrexone, a $\mu$-opioid antagonist, diminished heterosexual men's liking for highly attractive female faces. In a similar vein, Mallik, Chandra and Levitin ${ }^{111}$ reported that subjects experienced reduced pleasure for music when administered naltrexone.

Does a diminished ability to experience pleasure reduce the ability to experience stimuli specifically as beautiful? Brielmann and Pelli ${ }^{44}$ recently investigated this question by asking a cohort of participants varying in the ability to experience pleasure, with some exhibiting high degrees of anhedonia, to rate images according to their perceived beauty. Results of this study indicate that being unable to experience pleasure indeed reduces the possibility of experiencing images as beautiful. As Brielmann and Pelli ${ }^{44}$ concluded, being able to experience something as pleasurable is a prerequisite to experiencing it as beautiful.

\section{Beauty and Cognition}

All of the aforementioned results suggest that when humans appraise the beauty of objects, they engage mechanisms that evolved to compute hedonic pleasure signals. In terms of its affective component, beauty might thus simply be another name for pleasure. Yet, even though current evidence strongly implies that pleasure judgments and beauty judgments tap into a common affective system, studies have also found that pleasure and beauty are not equivalent.

Russell and George ${ }^{102}$ demonstrated that even though judgments of likeability, pleasingness, and preferability were highly correlated, different perceptual features varied in the degree to which they influenced the three types of evaluative judgments. For example, painting style was a strong predictor of pleasingness, but a weak 
predictor of preferability, and had no significant influence on likeability judgments. Other studies have found similar effects. ${ }^{103-106}$ Such results suggest that different forms of evaluative judgments lead people to weigh different aspects of the stimulus when they assess its aesthetic value. In other words, we may have different beliefs as to what counts as "attractive," "likable," "beautiful," and so on. These prior models may conceivably affect how we represent and process a stimulus during evaluation events, modulating the kind of perceptual and affective information that is deemed sufficient to warrant a specific evaluative judgment ("This stimulus is beautiful").

In a recent experiment we tested if beauty judgments engage executive processes involved in the formation of explicit evaluations in a different way than liking judgments. ${ }^{107}$ Participants were asked to rate the same set of paintings using both judgments types. The task of making an aesthetic judgment was embedded into a n-back working memory task manipulating the load of visual working memory throughout the aesthetic rating task. Results revealed that, while beauty and liking ratings were unaffected by memory load, the two judgment types interacted differently with the memory task. Specifically, beauty judgments led participants to make more mistakes and respond slower on the memory task, suggesting that evaluating beauty is more cognitively tasking than evaluating liking.

It remains unclear what defines an evaluative experience as beautiful. Data from Brielmann and Pelli's work ${ }^{44}$ indicate that people only consider stimuli for which they feel intense pleasure to be beautiful. Other expectations people may have for beautiful objects might include stimulus category, complexity, originality, or uniqueness - factors used to define beauty in the philosophical tradition. Further research is needed in order to describe the conceptual expectations people bring to beauty judgments, and how predictions arising from such conceptions influence neural processing during evaluation events. We also need neuroscientific work investigating how expectations about beauty modulate hedonic evaluation compared with other appraisal tasks.

\section{Beauty and Behavior}

Just as other forms of hedonic evaluation influence the way we interact with objects we encounter, beauty responses affect decision-making and behavior. ${ }^{108}$ Perceived beauty especially impacts our engagement with other people, the 
architectural spaces we create and inhabit, and consumer products we choose to purchase and use. In all of these cases, beauty has a substantial impact on affect, behavior, and choices.

Faces and bodies are highly socially informative, and they are the central focus of attention and valuation when people meet each other. Faces tell of others' sex, age, strength, lifestyle, and constitute the bases for inferences about psychological qualities, such as personality, intelligence and trustworthiness, and they influence people's attitudes and behavior towards others. The elements upon which valuation of facial attractiveness is based are remarkably common across cultures: averageness, symmetry, sexually dimorphic traits, and emotional expressiveness. ${ }^{18,37}$ Faces with average traits (e.g., distance between the eyes, nose and lip size) are generally found more attractive, ${ }^{38,109}$ and so are symmetrical faces. ${ }^{39,110}$ Female faces are more attractive when they have exaggerated — to a point — features that distinguish them from male faces, such as smaller than average noses and chins. Likewise, male faces are more attractive when they the features that distinguish them from female faces, such as strong square chins and heavy brows, are slightly above average. ${ }^{15}$ People also find faces expressing positive emotions - smiling faces - more attractive than emotionally neutral faces. ${ }^{111}$ Symmetry, exaggerated sexual dimorphic features, and emotional expressiveness also influence the attractiveness of bodies and movements. ${ }^{112-114}$ Despite these general trends, context, culture, and personal circumstances mediate the effects of facial and body features on attractiveness. ${ }^{115,116}$

Perceived beauty substantially affects how we evaluate other people's behaviors and personal attributes. Specifically, attractive individuals are attributed more positive personal and interpersonal qualities (such as trustworthiness, intelligence and social competence) than less attractive individuals. ${ }^{117,118}$ This association emerges quite early in development, and influences the way people treat others. ${ }^{119}$ Attractive children and adults are treated better, and given better opportunities, than unattractive people. This is the case even in contexts in which such differential treatment is discouraged or even against the law, including school classrooms, job interviews, salary negotiations, and court sentences. ${ }^{37,120}$ In tandem with this beautiful-is-good stereotype, people's judgments are influenced by ugly- and disfigured-is-bad stereotypes. ${ }^{119,121}$ People attribute negative personal traits to others with facial disfigurement: they view them with less empathic concern, as sources of negative affect, as less emotionally stable, less conscientious, less happy, less 
intelligent, less trustworthy, and less popular. ${ }^{121,122}$ Not surprisingly, most people expend great resources, both in terms of time and money, on improving how attractive they appear to others.

Beauty is also an integral aspect of how people respond to design. People in industrialized countries can spend upwards of $90 \%$ of their lives in buildings, ${ }^{123,124}$ interacting with an enormous assortment of human made and designed objects. One of the greatest challenges of architectural and consumer product design is to produce buildings and products where aesthetic features, such as beauty or elegance, and practical features, such as navigability, engineering, durability, and usability, blend and highlight each other. The aesthetic qualities of architecture, such as ceiling height, openness, and curvature have an impact on people's emotions, cognitive functioning, choices, and behavior. ${ }^{125-127}$ They have the potential to entice people to enter and explore further, or to dissuade them from doing so. ${ }^{77}$ With easy access to a plethora of options for many classes of consumer products, from cellular phones to furniture and home appliances, people find it increasingly difficult to choose based on price, technical specifications, or quality. Consumer choices are, therefore, often mainly driven by aesthetic features of product design, packaging, shop displays and interiors, websites, and commercials. ${ }^{128}$ The beauty of consumer products, and of the stores that sell them, influences purchase intentions, word of mouth, and willingness to pay. ${ }^{129-}$ ${ }^{131}$ As with faces, the beauty of buildings and products is taken as a proxy indicating good buildings and products.

\section{Beauty is not Uniquely Human}

One of the long-lasting consequences of the Great Theory of Beauty is the widely held assumption that the appreciation of beauty is an exclusively human attribute. The renowned geneticist Theodosius Dobzhansky ${ }^{132}$ wrote that "Sensitivity to beauty and making or doing things that are perceived as 'beautiful' are among the traits that elevate man above the brutes" (p. 214). If true, this would imply that Homo sapiens evolved a unique set of neurobiological mechanisms associated with hedonic evaluation that set human beauty responses apart from other pleasure responses experienced by non-human animals.

But beauty, understood as the hedonic value assigned to perceptual objects, modulated by interoceptive signals and cognitive control, is ubiquitous in the animal 
world. Birdsong, bowers, colors of bird plumage, fish, and insects, are examples of natural beauty. Hedonic valuation is a means the brain has of orienting an organism towards objects and places that are meaningful, that matter for survival, by imbuing them with reward value and incentive salience. The role of hedonic valuation is key in foraging, predator avoidance, and finding and choosing suitable mates.

Many of the most remarkable examples of animal beauty are related to mating. ${ }^{7}$ Darwin ${ }^{133}$ argued that the evolution of sexual beauty in animals owed to sexual selection, or the competition for access to mates. ${ }^{134}$ Mate choice, he thought, was driven by "a taste for the beautiful," that is to say, by an attraction to ornate bowers, complex and varying songs, elaborate sequences of movements, and colorful bodies and plumage. ${ }^{7,8}$ Most explanations for the role of beauty in mating preferences focused on the information provided by male ornaments: the best quality and quantity of ornaments indicate the best genes. However, with questions about the strength of the evidence for "good genes" explanations, and with a growing understanding of the underlying neural systems, the focus is shifting toward the processes involved in females' valuation of beauty ${ }^{1}{ }^{135}$

The features that bias animals towards or away from objects that are relevant to individual and species survival share many commonalities with human hedonic valuation. These include preference for fluency, or ease of processing, preference for symmetry and prototypes as a result of learning and categorization processes, and preference for interestingness, as in complexity and variety, as a remedy for habituation. ${ }^{8}$ The consistency with which many animal species, including our own, rely on such features to value the environment and conspecifics around them is striking.

Moreover, just as in the case of humans, animal hedonic valuation is not fixed and absolute; it is not merely a case of set stimulus-response sequences. Hedonic valuation in animals is flexible and context-dependent, modulated by the organism's state and goals. ${ }^{136}$ Responses to mate signals change in time, as with age and time since the initiation of courtship, and with social context, as with mate choice copying, and are weighed relative to other less preferable alternatives. ${ }^{8,137}$

\footnotetext{
${ }^{1}$ We are grateful to an anonymous reviewer for brining to our attention that this shift parallels the change from a conception of beauty as a quality of an object to a conception of beauty as a quality of an experience, described above.
} 
There is a remarkable continuity between human and non-human animal hedonic valuation. Hedonic valuation, in humans and other animals, responds to similar features, such as fluency, symmetry, and complexity, and it is modulated by similar factors, such as time, social imitation, and available alternatives. Thus, human beauty appreciation is rooted in basic animal mechanisms of hedonic valuation that orient animals towards or away from social and non-social objects and places that are significant for survival by imbuing them with reward value and incentive salience.

Looked at through the lens of science, beauty is not the pinnacle of human realization, and it certainly does not elevate humans above other animals. Beauty is born out of mechanisms that regulate basic biological needs, common to many classes of animals. A greater awareness that many species of mammals, birds, amphibians, and fish experience something akin to beauty could go a long way toward changing attitudes towards their welfare and conservation.

\section{Conclusion}

Beauty is a concept that has attracted intellectual interest for at least three millennia. In the Western philosophical tradition, it has come to signify a psychological response that is unique to humans, characterized by the experience of disinterested pleasure for certain select categories of sensory objects. As our review shows, this inherited view is contradicted by contemporary empirical evidence. Findings from psychological, neuroscientific, and biological research suggest that beauty should be conceived as a form of basic hedonic valuation that humans share with other animals: only sensory objects that elicit hedonic pleasure are experienced as beautiful. Like taste responses for food and drink, beauty responses appear to involve the activation of pleasure signals that are common to other forms of hedonic valuation. Crucially, hedonic valuation is generally assumed to function as motivational signal, biasing behavior in ways that are adaptive to survival. Experiments in many domains find beauty responses to affect behavior in a similar way.

What makes beauty evaluations different to other types of hedonic evaluation are the cognitive processes they appear to involve (Figure 3). As noted above, context, expectations, and task demands modulate both the perceptual representation of the object being appraised and the ensuing reward signals, influencing the appraisal 
of beauty. People and animals have complex expectations of what beauty is, what it means and what it signals, and such expectations play an important role in appraising beauty, and in responding to it. Based on our current understanding of beauty judgments, we suggest the hypothesis that making explicit decisions about whether an object is beautiful or not involves matching conceptual models of what counts as beautiful with online representations of its perceptual, cognitive, and hedonic properties (Figure 3).

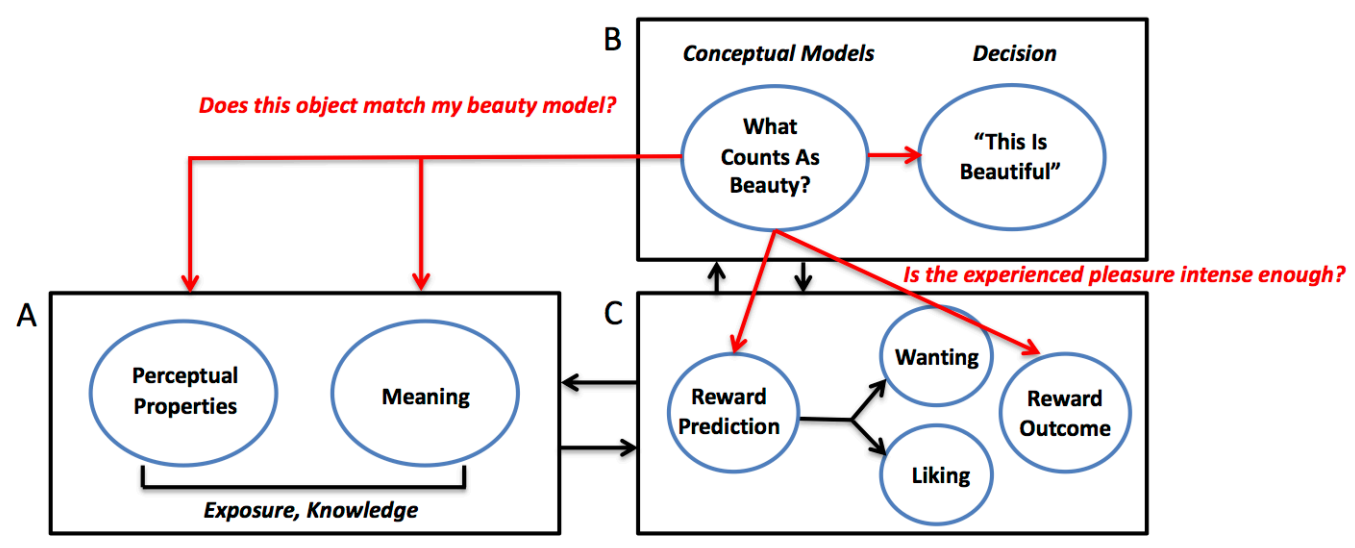

Figure 3. A possible computational architecture for beauty judgments. Experiments suggest that, in making explicit beauty judgments, people rely on conceptual models of what counts as beauty; models that are represented by executive mechanisms in the prefrontal cortex (B). These models set up expectations for what kind of perceptual properties (A), and hedonic values (C), a given stimulus must match in order to qualify as beautiful. Therefore, beauty decisions involve maintaining perceptual and hedonic information online in working memory, and other structures underlying decision-making (B), while comparisons of these with initial expectations are conducted. For example, data from Brielmann and Pelli (2019) suggest that only when a stimulus elicits high levels of hedonic pleasure does it qualify as beautiful.

The scientific study of beauty remains in its infancy. It has been held back by untested assumptions that treat beauty as a distinct class of experience defined by a special kind of pleasure that is unique to humans in response to certain objects. A mature science of beauty will only be possible if we continue to bring such assumptions into the light, subject them to experimental test, and reject those that are not supported by the data. As we have shown above, empirical studies present a completely different picture of the nature of beauty. This picture is now clear enough 
for psychologists and neuroscientists to begin outlining the computational, functional, and physiological features characteristic of beauty responses and judgments.

\section{References}

${ }^{1 .}$ Brody, H. 2015. Nature Outlook: Beauty. Nature 7572: S1-S17.

2. Cattaneo, Z. 2019. Noninvasive brain stimulation: An overview of available approaches for research in neuroaesthetics. Empirical Studies of the Arts 37: 153-171.

3. Chatterjee, A. 2014. The Aesthetic Brain. How we Evolved to Desire Beauty and Enjoy Art. Oxford: Oxford University Press.

${ }^{4 .}$ Huston, J.P., M. Nadal, F. Mora, et al. 2015. Art, Aesthetics and the Brain. Oxford: Oxford University Press.

${ }^{5 .}$ Ishizu, T. 2019. Functional neuroimaging in empirical aesthetics and neuroasthetics. In The Oxford Handbook of Empirical Aesthetics. M. Nadal \& O. Vartanian, Eds.: 133. Oxford: Oxford University Press. DOI: 10.1093/oxfordhb/9780198824350.013.14

6. Skov, M. \& O. Vartanian. 2009. Neuroaesthetics. Amityville, NY: Baywood Publishing Company.

7. Prum, R.O. 2017. The Evolution of Beauty: How Darwin's Forgotten Theory of Mate Choice Shapes the Animal World - and Us. New York: Doubleday.

${ }^{8 .}$ Ryan, M. J. 2018. A Taste for the Beautiful. The Evolution of Attraction. Princeton: Princeton University Press.

9. Skov, M. (Submitted). Animal preferences: implications of sexual selection research for empirical aesthetics.

10. Conway, B.R. \& A. Rehding. 2013. Neuroaesthetics and the trouble with beauty. PLoS Biology: e1001504.

${ }^{11 .}$ Redies, C. (2014). Beauty: Neglected, but alive and kicking. British Journal of Psychology 105: 468-470.

12. Chatterjee, A. \& O. Vartanian. 2016. Neuroscience of aesthetics. Annals of the New York Academy of Sciences 1369: 172-194.

13. Salimpoor, V.N. \& R.J. Zartorre. 2013. Neural interactions that give rise to musical pleasure. Psychology of Aesthetics, Creativity, and the Arts 7: 62-75. 
14. Skov, M. 2019. The neurobiology of sensory valuation. In The Oxford Handbook of Empirical Aesthetics. M. Nadal \& O. Vartanian, Eds.: 1-40. Oxford: Oxford

University Press. DOI: 10.1093/oxfordhb/9780198824350.013.7

15. Johnston, V. S. 2006. Mate choice decisions: The role of facial beauty. Trends in Cognitive Sciences 10: 9-13.

16. Little, A.C. \& B.C. Jones. 2009. The evolutionary cognitive neuropsychology of face preferences. In Foundation in Evolutionary Cognitive Neuroscience. S.M. Platek \& T.K. Shackelford, Eds.: 175-204. Cambrudge, UK: Cambridge University Press.

17. Little, A.C., B.C. Jones \& L.M. DeBruine. 2011. Facial attractiveness:

Evolutionary based research. Philosophical Transactions of the Royal Society of London B 366: 1638-1659.

18. Rhodes, G. 2006. The evolutionary psychology of facial beauty. Annual Review of Psychology 57: 199-226.

19. Dieckmann, H. 1974. Theories of beauty to the mid-nineteenth century. In Dictionary of the History of Ideas, Vol. I. P.P. Wiener, Ed.: 195-206. New York: Charles Scribner's Sons.

20. Stolnitz, J. 1961. "Beauty": Some stages in the history of an idea. Journal of the History of Ideas 22: 185-204.

21. Beardsley, M. C. 1966. Aesthetics from Classical Greece to the Present. A Short History. The University of Alabama Press.

22. Sparshott, F. E. 1963. The Structure of Aesthetics. Toronto: Toronto University Press.

23. Tatarkiewicz, W. 1970. History of Aesthetics: Vol. I. Ancient. Bristol: Thoemmes Press.

24. Tatarkiewicz, W. 1972. The great theory of beauty and its decline. The Journal of Aesthetics and Art Criticism 31: 165-180.

25. Kivy, P. 2003. The Seventh Sense: Francis Hutcheson and Eighteenth-Century Aesthetics. Oxford: Oxford University Press.

26. Townsend, D. 1987. From Shaftesbury to Kant. The development of the concept of aesthetic experience. Journal of the History of Ideas 48: 287-305.

27. Kant, I. 2001. Critique of the Power of Judgment. P. Guyer \& E. Matthews, Trans.; Rev. Ed.. Cambridge, England: Cambridge University Press.

28. Stolnitz, J. 1961. On the origins of "aesthetic disinterestedness". The Journal of Aesthetics and Art Criticism 20: 131-143. 
29. Carroll, N. 2002. Aesthetic experience revisited. British Journal of Aesthetics 42: $145-168$.

30. Shiner, L. 2001. The Invention of Art: A Cultural History. Chicago: University of Chicago Press.

31. Wilcox, J. 1953. The Beginnings of l'Art Pour l'Art. The Journal of Aesthetics and Art Criticism 11: 360-377.

32. Valentine, C.W. 1962. The Psychology of Beauty. London: Methuen \& Co LTD.

33. Anglada-Tort, M. \& M. Skov (2020). What counts as aesthetics in science? A bibliometric analysis and visualization of the scientific literature from 1970 to 2018. Psychology of Aesthetics, Creativity and the Arts. DOI: 10.1037/aca0000350

34. Berlyne, D. E. 1971. Aesthetics and Psychobiology. Appleton-Century-Crofts.

35. Berlyne, D. E. 1974. Studies in the New Experimental Aesthetics: Steps toward an Objective Psychology of Aesthetic Appreciation. Hemisphere Publishing Corporation.

36. Skov, M. 2019. Aesthetic appreciation: The view from neuroimaging. Empirical Studies of the Arts 37: 220-248.

37. Langlois, J. H., L. Kalakanis, A.J. Rubenstein, et al. 2000. Maxims or myths of beauty? A meta-analytic and theoretical review. Psychological Bulletin 126: 390-423.

38. Langlois, J. H., \& L.A. Roggman. 1990. Attractive faces are only average. Psychological Science 1: 115-121.

39. Perrett, D. I., D.M., Burt, I.S. Penton-Voak, et al. (1999). Symmetry and human facial attractiveness. Evolution and Human Behavior 20: 295-307.

40. Ferreri L, E. Mas-Herrero, R.J. Zatorre RJ, et al. 2019, Dopamine modulates the reward experiences elicited by music. Proceedings Of The National Academy Of Sciences Of The United States Of America 116: 3793 - 3798.

41. Gold, B.P., E. Mas-Herrero, Y. Zeighami, et al. 2019. Musical reward prediction errors engage the nucleus accumbens and motivate learning. Proc. Natl. Acad. U.S.A. 116: $3310-3315$.

42. Salimpoor, V. N., M. Benovoy, K. Larcher, et al.. 2011. Anatomically distinct dopamine release during anticipation and experience of peak emotion to music. Nature Neuroscience 14. 257-262.

43. Salimpoor, V.N., I. van den Bosch, N. Kovacevic, et al. (2013). Interactions between the nucleus accumbens and auditory cortices predicts music reward value. Science 340: 216-219.

44. Brielmann, A. A. \& D.G. Pelli. 2019. Intense beauty requires intense pleasure. Frontiers in Psychology 10: 2420. https://doi.org/10.3389/fpsyg.2019.02420 
${ }^{45 .}$ Corradi, G., M. Belman, T. Currò, et al. 2019. Aesthetic sensitivity to curvature in real objects and abstract designs. Acta Psychologica 197: 124-130.

46. Corradi, G., E.G. Chuquichambi, J.R. Barrada, et al. 2019. A new conception of visual aesthetic sensitivity. British Journal of Psychology. DOI: 10.1111/bjop.12427

47. Skov, M. \& M. Nadal. 2019. The nature of perception and emotion in aesthetic appreciation: A response to Makin's challenge to Empirical Aesthetics. Psychology of Aesthetics, Creativity and the Arts. DOI:10.1037/aca0000278

48. Skov, M. \& M. Nadal. 2020. A farewell to art: Aesthetics as a topic in psychology and neuroscience. Perspectives on Psychological Science 15: 630-642.

49. Berridge, K.C. \& M.L. Kringelbach. 2015. Pleasure systems in the brain. Neuron 86: 646-664.

50. Bartra, O., J.T. McGuire \& J.W. Kable. 2013. The valuation system: A coordinatebased meta-analysis of BOLD fMRI experiments examining neural correlates of subjective value. Neuroimage 76: 412-427.

51. Bzdok, D., R. Langner, S. Caspers, et al. 2010. ALE meta-analysis on facial judgments of trustworthiness and attractiveness. Brain Structure and Function 215: 209-223.

52. Brown, S., X. Gao, L. Tisdelle, et al. (2011). Naturalizing aesthetics: Brain areas for aesthetic appraisal across sensory modalities. NeuroImage 58: 250-258.

53. Kühn, S. \& J. Gallinat. 2012. The neural correlates of subjective pleasantness. Neuroimage 61: 289-294.

54. Sescousse, G., X. Caldú, B. Segura, et al. 2013. Processing of primary and secondary rewards: A quantitative meta-analysis and review of human functional neuroimaging studies. Neuroscience and Biobehavioral Reviews 37: 681-696.

55. Vartanian, O. \& M. Skov. 2014. Neural correlates of viewing paintings: Evidence from a quantitative meta-analysis of functional magnetic resonance imaging data. Brain and Cognition 87: 52-56.

56. Pessiglione, M. \& M.R. Delgado. 2015. The good, the bad and the brain: Neural correlates of appetitive and aversive values underlying decisión making. Current Opinion in Behavioral Science 5: 78-84.

57. Klebl, C., K.H. Greenaway, J.J. Rhee, J.J. B. \& Bastian. 2020. Ugliness judgments alert us to cues of pathogen presence. Social Psychological and Personality Science. DOI: $10.1177 \% 2$ F1948550620931655

58. Peciña, S., K.S. Smith \& K.C. Berridge. 2006. Hedonic hot spots in the brain. The Neuroscientist 12: 500-511.

59. Berridge, K.C. 2019. Affective valence in the brain: modules or modes? Nature 
Reviews Neuroscience 20: 225-234.

60. Berridge, K.C. \& T.E. Robinson. 2003. Parsing reward. Trends in Neurosciences 26: $507-513$.

61. Pessiglione, M. \& M. Lebreton. 2015. From the reward curcuit to the valuation system: How the brain motivates behavior. In Handbook of Biobehavioral Approaches to Self-Regulation. G.H.E. Gendolla et al., Eds.: 157-173. New York: Springer.

62. Dayan, P. \& N.D. Daw. 2008. Decision theory, reinforcement learning, and the brain. Cognitive, Affective, and Behavioral Neuroscience 8: 429-453.

63. Juechems, K. \& C. Summerfield. 2019. Where does value come from? Trends in Cognitive Sciences 23: 836-850.

64. Bohrn, I. C., U. Altmann, O. Lubrich, et al. 2013. When we like what we know-a parametric fMRI analysis of beauty and familiarity. Brain and Language 124: 1-8.

${ }^{65 .}$ Flexas, A., J., Roselló, P. de Miguel, et al. 2014. Cognitive control and unusual decisions about beauty: an fMRI study. Frontiers in Human Neuroscience 8: 520.

66. Gao, G. \& G. Guo. 2018. The experience of beauty of Chinese poetry and its neural substrates. Frontiers in Psychology 9: 1540.

67. Ishizu, T. \& S. Zeki. 2013. The brain's specialized systems for aesthetic and perceptual judgment. European Journal of Neuroscience 37: 1413-1420.

68. Ishizu, T. \& S. Zeki. 2014. Toward a brain-based theory of beauty. PLoS ONE 6: e21852.

69. Ishizu, T. \& S. Zeki. 2017. The experience of beauty derived from sorrow. Human Brain Mapping 38: 4185-4200.

70. Jacobs, R., R. Renken \& F.W. Cornelissen. 2012. Neural correlates of visual aesthetics - Beauty as the coalescence of stimulus and internal state. PLoS One 7: e31248.

71. Kawabata, H. \& S. Zeki. 2004. Neural correlates of beauty. Journal of Neurophysiology 91: 1699-705.

72. Kedia, G., T. Mussweiler, P. Mullins \& D.E.J. Linden. 2014. The neural correlates of beauty comparison. SCAN 9: 681-688.

73. Kornysheva, K., D.Y. von Cramon, T. Jacobsen \& R.I. Schubotz. 2010. Tuning-in to the Beat: Aesthetic Appreciation of Musical Rhythms Correlates with a Premotor Activity Boost. Human Brain Mapping 31: 48-64. 
74. Martin-Loeches, M., J.A. Herrández-Tamames \& M. Urrutia. 2014. Beauty and ugliness in the bodies and faces of others: an fMRI study of person esthetic judgment. Neuroscience 277: 486-497.

75. Mizokami, Y., T. Terao, K. Hatano, et al. 2014. Difference in brain activations during appreciating paintings and photographic analogs. Frontiers in Human Neuroscience 8: 478.

76. Skov, M., M.S. Christensen, J.B. Rowe \& O.B. Paulson. 2005. Specific activations underlie aesthetic judgment of affective pictures. Neuroimage (Poster, HBM meeting, 2005).

77. Vartanian, O., G. Navarrete, A. Chatterjee, et al. 2014. Impact of contour on aesthetic judgments and approach-avoidance decisions in architecture. Proceedings of the National Academy of Sciences 110: 10446-10453

78. Wang, T., L. Mo, C. Mo, et al. 2015. Is moral beauty different from facial beauty? Evidence from an fMRI study. Social Cognitive and Affective Neuroscience 10: 814 823.

79. Zeki, S., J.P. Romaya, D.M.T. Benincasa \& M.F. Atiyah. 2014. The experience of mathematical beauty and its neural correlates. Frontiers in Human Neuroscience 8: 68.

80. Zhang, W., S. Lai, X. He, et al. 2016. Neural correlates for aesthetic appraisal of pictograph and its referent: An fMRI study. Behavioural Brain Research 305: 229238.

81. Zhang, W., X. He, S. Lai, et al. 2017. Neural substrates of embodied natural beauty and social endowed beauty: An fMRI study. Scientific Reports 7: 7125.

82. Chatterjee, A., A. Thomas, S.E. Smith \& G.K. Aguirre. 2009. The neural response to facial attractiveness. Neuropsychology 23: 135-143.

83. Jacobsen, T., R.I. Schubotz, L. Höfel \& D.Y. v. Cramon. 2006. Brain correlates of aesthetic judgment of beauty. Neuroimage 29: 276-285.

84. Kim, H., R. Adolphs, J.P. O’Doherty \& S. Shimojo. 2007. Temporal isolation of neural processes underlying face preference decisions. Proceedings of the National Academy of Sciences 104: 18253-18258.

85. Becker, S., A.K. Bräscher, S. Bannister, et al.. (2019). The role of hedonics in the Human Affectome. Neuroscience and Biobehavioral Reviews 102: 221-241.

86. Berridge, K.C. 2003. Comparing the emotional brain of humans and other animals. In Handbook of Affective Sciences. R.J. Davidson, H.H. Goldsmith \& K. Scherer, Eds.: 25-51. Oxford: Oxford University Press.

87. Panksepp, J. 1998. Affective Neuroscience. Oxford: Oxford University Press. 
88. Berlyne, D. E. 1973. Interrelations of verbal and nonverbal measures used in experimental aesthetics. Scandinavian Journal of Psychology 14: 177-184.

89. Berlyne, D. E. 1974. Verbal and exploratory responses to visual patterns vaying in uncertainty and in redundancy. In Studies in the new experimental aesthetics: Steps toward an objective psycholoy of aesthetic appreciation. D. E. Berlyne, Ed.: 121-158. Washington, D. C.: Hemisphere Publishing Corporation.

${ }^{90 .}$ Berlyne, D. E. \& J.C. Ogilvie. 1974. Dimensions of perception of paintings. In Studies in the new experimental aesthetics: Steps toward an objective psychology of aesthetic appreciation. D. E. Berlyne, Ed.: 181-226. Washington, D. C.: Hemisphere Publishing Corporation.

91. Crozier, J. B. 1974. Verbal and exploratory responses to sound sequences varying in uncertainty level. In Studies in the new experimental aesthetics: Steps toward an objective psychology of aesthetic appreciation. D. E. Berlyne, Ed.: 27-90.

Washington, D. C.: Hemisphere Publishing Corporation.

92. Marty, G., C.J. Cela-Conde, E. Munar, et al. 2003. Dimensiones factoriales de la experiencia estética. Psicothema 15: 478-483.

93. Normore, L. F. 1974. Verbal responses to visual sequences varying in uncertainty level. In Studies in the new experimental aesthetics: Steps toward an objective psychology of aesthetic appreciation. D. E. Berlyne, Ed.: 109-120. Washington, D. C.: Hemisphere Publishing Corporation.

94. Oostendorp, A. \& D.E. Berlyne. 1978. Dimensions in the perception of architecture I. Identification and interpretation of dimensions of similarity. Scandinavian Journal of Psychology 19: 73-82.

95. O'Hare, D. P. A., \& I.E. Gordon. 1977. Dimensions of the perception of art: Verbal scales and similarity judgments. Scandinavian Journal of Psychology 18: 66-70.

96. Biaggio, M. K. \& K.A. Supplee. 1983. Dimensions of aesthetic perception. The Journal of Psychology 114: 29-35.

97. Hagtvedt, H., R. Hagtvedt \& V.M. Patrick. 2008. The perception and evaluation of visual art. Empirical Studies of the Arts 26: 197-218.

98. Hager, M., D. Hagemann, D. Danner \& A. Schankin. 2012. Assessing aesthetic appreciation of visual artworks - The construction of the Art Reception Survey (ARS). Psychology of Aesthetics, Creativity, and the Arts 6: 320-333.

99. Katsuura, Y., J.A. Hexkmann \& S.A. Taha. 2011. $\mu$-Opioid receptor stimulation in nucleus accumbens elevates fatty tastant intake by increasing palability and suppressing satiety signals. American Journal of Physiology 301: R244-R254.

${ }^{100 .}$ Chelnokova, O., B. Laeng, M. Eikemo, et al. 2014. Rewards of beauty: The opioid system mediates social motivation in humans. Molecular Psychiatry 19: 746-747. 
${ }^{101 .}$ Mallik, A., M.L. Chanda \& D.J. Levitin. 2017. Anhedonia to music and muopioids: Evidence from the administration of naltrexone. Scientific Reports, 7: 41952.

102. Russell, P. A. \& D.A. George. 1990. Relationships between aesthetic response scales applied to paintings. Empirical Studies of the Arts 8: 15-30.

103. Marin, M. M., A. Lampatz, M. Wandl \& H., Leder. 2016. Berlyne revisited: Evidence for the multifaceted nature of hedonic tone in the appreciation of paintings and music. Frontiers in Human Neuroscience 10: 536.

104. Russell, P. A. 1994. Preferability, pleasingness, and interestingness: Relationships between evaluative judgments in empirical aesthetics. Empirical Studies of the Arts 12: 141-157.

105. Russell, P. A. \& C.D. Gray. 1991. The heterogeneity of the preferability scale in aesthetic judgments of paintings. Visual Arts Research 17: 76-84.

106. Sidhu, D. M., K.H. McDougall, S.T. Jalava \& G.E. Bodner 2018. Prediction of beauty and liking ratings for abstract and representational paintings using subjective and objective measures. PLoS One 13: e0200431.

107. Che, J., Sun, X., Skov, M., Vartanian, O., \& Nadal, M. Submitted. Judging beauty requires more working memory resources than judging liking.

108. Maestripieri, D., A. Henry, \& N. Nickels. 2016. Explaining financial and prosocial biases in favor of attractive people: Interdisciplinary perspectives from economics, social psychology, and evolutionary psychology. Behavioral \& Brain Sciences 40: e19. doi:10.1017/S0140525X16000340

109. Rhodes, G., A. Sumich \& G. Byatt. 1999. Are average facial configurations attractive only because of their symmetry? Psychological Science 10: 52-58.

110. Rhodes, G., F. Proffitt, J.M. Grady \& A. Sumich. 1998. Facial symmetry and the perception of beauty. Psychonomic Bulletin and Review 10: 52-58.

111. O'Doherty, J. P., J. Winston, H.D. Critchley, et al. 2003. Beauty in a smile: the role of medial orbitofrontal cortex in facial attractiveness. Neuropsychologia 41: 147155.

112. Aglioti, S. M., I. Minio-Paluello, \& M. Candidi. 2012. The beauty of the body. Rendiconti Lincei 23: 281-288.

113. Calvo-Merino, B., C. Jola, D.E. Glaser \& P. Haggard. 2008. Towards a sensorimotor aesthetics of performing art. Consciousness and Cognition 17: 911-922.

114. Orgs, G., N. Hagura \& P. Haggard. 2013. Learning to like it: Aesthetic perception of bodies, movements and choreographic structure. Consciousness and Cognition 22: $603-612$. 
${ }^{115 .}$ Little, A. C., B. Jones, I.S. Penton-Voak, et al. (2002). Partnership status and the temporal context of relationships influence human female preferences for sexual dimorphism in male face shape. Proceedings of the Royal Society B: Biological Sciences 269: 1095-1110.

116. Mitrovic, A., J. Goller, P.P.L. Tinio \& H. Leder. 2018. How relationship status and sociosexual orientation influence the link between facial attractiveness and visual attention. PLOS ONE 13: e0207477.

117. Dion, K., E. Berscheid \& E. Walster. 1972. What is beautiful is good. Journal of Personality and Social Psychology 24: 285-290.

118. Eagly, A.H., R.D. Ashmore, M.G. Makhijani \& L.C. Longo. 1991. What is beautiful is good, but..: A meta-analytic review of research on the physical attractiveness stereotype. Psychological Bulletin 110: 109-128.

119. Griffin, A. M. \& J.H. Langlois. 2006. Stereotype directionality and attractiveness stereotyping: Is beauty good or is ugly bad? Social Cognition 24: 187-206.

${ }^{120 .}$ Frevert, T. K. \& L.S. Walker. 2014. Physical attractiveness and social status. Sociology Compass 8: 313-323.

121. Jamrozik, A., M.O. Ali, D.B. Sarwer \& A. Chatterjee. 2019. More than skin deep: Judgments of individuals with facial disfigurement. Psychology of Aesthetics, Creativity, and the Arts 13: 117-129.

122. Hartung, F., A. Jamrozik, M.E. Rosen, et al.. (2019). Behavioural and Neural Responses to Facial Disfigurement. Scientific Reports 9: 8021. DOI: 10.1038/s41598019-44408-8.

123. Klepeis, N. E., W.C. Nelson, W.R. Ott, et al. (2001). The National Human Activity Pattern Survey (NHAPS): a resource for assessing exposure to environmental pollutants. Journal of Exposure Analysis and Environmental Epidemiology 11: 231252.

124. Schweizer, C., R.D. Edwards, L. Bayer-Oglesby, et al. (2007). Indoor timemicroenvironment-activity patterns in seven regions of Europe. Journal of Exposure Science and Environmental Epidemiology 17: 170-181.

125. Aries, M. B. C., J.A. Veitch \& G.R. Newsham. 2010. Windows, view, and office characteristics predict physical and psychological discomfort. Journal of Environmental Psychology 30: 533-541.

126. Fich, L. B., P. Jönsson, P.H. Kirkegaard, et al. (2014). Can architectural design alter the physiological reaction to psychosocial stress? A virtual TSST experiment. Physiology \& Behavior 135: 91-97.

127. Ulrich, R. S. 1991. Effects of interior design on wellness: theory and recent scientific research. Journal of Health Care Interior Design 3: 97-109. 
128. Patrick, V. M. 2016. Everyday consumer aesthetics. Current Opinion in Psychology 10: 60-64.

129. Ho, C.H., Y.N. Lu \& C.H. Chen. 2016. Influence of curvature and expertise on aesthetic preferences for mobile device designs. International Journal of Design 10: $17-25$.

${ }^{130 .}$ Homburg, C., M. Schwemmle \& C. Kuehnl. 2015. New product design: Concept, measurement, and consequences. Journal of Marketing 79: 41-56.

131. Reimann, M., J. Zaichkowsky, C. Neuhaus, et al. (2010). Aesthetic package design: A behavioral, neural, and psychological investigation. Journal of Consumer Psychology 20: 431-441.

132. Dobzhansky, T. (1962). Mankind Evolving. The Evolution of the Human Species. Yale: Yale University Press.

133. Darwin, C. 1871. The Descent of Man, and Selection in Relation to Sex. London: John Murray.

134. Jones, A. \& N. Ratterman. 2009. Mate choice and sexual selection: what have we learned since Darwin? Proceedings of the National Academy of Sciences of the United States of America 106: S10001-S10008.

135. Achorn, A. M. \& G.G. Rosenthal. 2020. It's Not about Him: Mismeasuring "Good Genes" in Sexual Selection. Trends in Ecology \& Evolution 35: 206-219.

https://doi.org/10.1016/j.tree.2019.11.007

136. Pflüger, L. S., C. Valuch, D.R. Gutleb, et al. (2014). Colour and contrast of female faces: attraction of attention and its dependence on male hormone status in Maccaca fuscata. Animal Behaviour 94: 61-71.

137. Ryan, M. J., R.A. Page, K.L. Hunter \& R.C. Taylor. 2019. 'Crazy love':

nonlinearity and irrationality in mate choice. Animal Behaviour 147: 189-198.

https://doi.org/10.1016/j.anbehav.2018.04.004 